\title{
编者按离子液体前沿专刊
}

\section{前言: 离子液体前沿专刊}

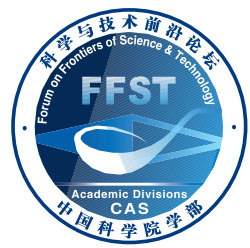

资源和能源革命不断孕育催生颠覆式创新技术. 离子液体作为新一代绿色介质和功能材料, 在替代传统技术 方面凸显卓越潜能. 经过二十余年的快速发展, 离子液体已成为当前国际科学与技术研究前沿, 并在工业化应用 方面不断取得突破. 离子液体研究蓬勃发展的态势, 展现了当今学科高度交叉融合的趋势以及离子液体领域广阔 的发展前景.

然而, 在离子液体工业化研究不断发展的过程中, 对离子液体及其复杂体系科学本质及规律性认识的不足已 逐渐成为阻碍其工业化应用的主要问题，这无疑为离子液体的基础研究、工程研究、应用拓展提供了原始创新 的空间和动力, 同时也为我们的研究提出了新的挑战.

为解决离子液体基础及应用研究中的关键科学问题、研讨新的发展前沿、建立学术思想交流平台, 中国化 工学会离子液体专业委员会于 2020 年陆续组织召开了第五届全国离子液体与绿色过程学术会议、第112次中国 科学院学部科学与技术前沿论坛——离子液体科学与工程、香山科学会议第693次学术讨论会——离子液体功 能调控及交叉融合前沿技术，吸引了众多专家及青年学者参会. 基于这三次以离子液体为主题的盛会，《中国科 学: 化学》特推出 “离子液体前沿”专刊. 本专刊包括14篇文章, 内容涉及离子液体的微观结构、物性、合成及其 在仿生催化、生物质转化、蛋白质分离、生物医药、电子器件、电容器、纳米颗粒制备、气体吸收分离、塑料 降解等领域中的应用, 展示了我国离子液体研究的新进展、新动态和新成果.

我们相信, 离子液体基础研究的创新必然带来化工、生物、材料、环境等交叉融合前沿技术的重要突破, 离 子液体的明天一定会更加美好. 我们希望本专刊能够对离子液体研究领域的发展具有积极的推动作用, 并能鼓励 更多的青年科技工作者加入到该领域.

作为本专刊的客座编辑, 我们对所有作者、审稿人和《中国科学: 化学》编辑部卓有成效的工作表示诚挚的 谢意!

王键吉 河南师范大学化学化工学院

张锁江 中国科学院过程工程研究所

韩布兴 中国科学院化学研究所

引用格式: Wang J, Zhang S, Han B. Preface: special issue on the frontiers of ionic liquids. Sci Sin Chim, 2021, 51: 1311-1312, doi: 10.1360/SSC-2021-0209 

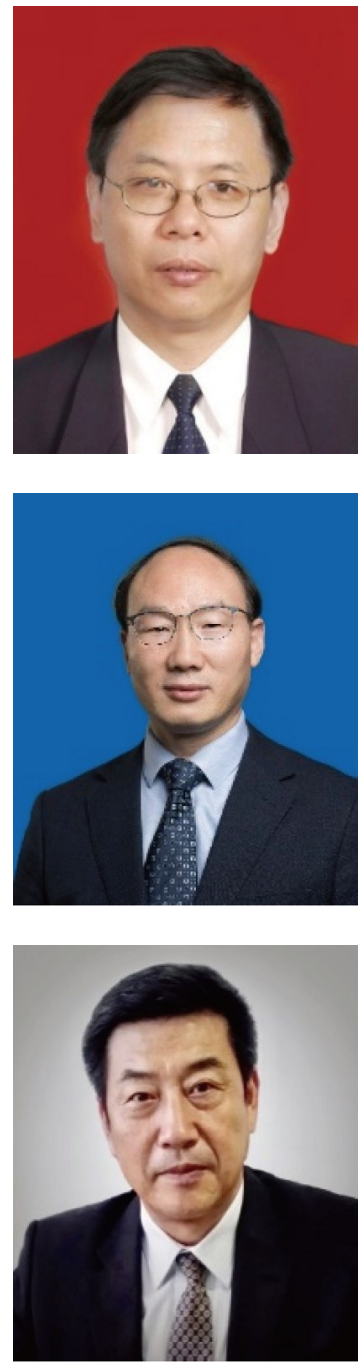

王键吉, 先后于河南师范大学、武汉大学、日本横滨国立大学获得学士、硕士和 博士学位. 现任河南师范大学化学化工学院教授、博士生导师, 绿色介质与反应 教育部重点实验室主任, 中国化学会化学热力学与热分析专业委员会主任, 中国 化工学会离子液体专业委员会副主任，英国皇家化学会会士，Green Energy \& Environment期刊副主编. 主要从事溶液化学、绿色介质化学的研究, 聚焦溶液体 系的微观结构、相行为与性能调控及其在可持续化学中的应用. 曾获国家自然科 学二等奖1项, 国家教学成果二等奖1项, 河南省科技进步一等奖2项.

张锁江, 1994年于浙江大学获博士学位, 现任中国科学院过程工程研究所所长. 中 国科学院院士. 主要从事离子液体与绿色过程研究. 提出了离子液体Z键新概念, 建立了离子液体分子设计及构效关系, 阐明了离子液体对反应和传递性能的影响 规律, 建立了离子液体三维原位研究装置, 实现了多套工业示范及应用, 突破了离 子液体规模制备、绿色工艺创新和系统集成的难题. 担任Green Energy \& Environment和《过程工程学报》期刊主编. 获国家自然科学二等奖、何梁何利科学与 技术进步奖、中科院科技促进发展奖、侯德榜化工科技成就奖等.

韩布兴, 中国科学院化学研究所研究员, 华东师范大学特聘教授, 英国诺丁汉大学 荣誉教授, 中国科学院院士, 发展中国家科学院院士. 1982年毕业于河北科技大学 (原河北化工学院)有机化工系, 1985年在中国科学院长春应用化学研究所获硕士 学位，1988年在中国科学院化学研究所获博士学位，1989 1991年在加拿大Saskatchewan大学做博士后研究. 担任中国化学会绿色化学专业委员会主任、北京 能源与环境学会会长、The Innovation期刊主编; 曾任国际纯粹与应用化学联合 会(IUPAC)绿色化学分会主席、IUPAC第三学部领衔委员、中国化学会化学热力 学与热分析专业委员会主任. 